\title{
EDUCAÇÃO FíSICA ESCOLAR: OS IMPACTOS SOCIAIS NA VIDA DE PESSOAS TRANSEXUAIS EM BELÉM DO PARÁ
}

\author{
LUCAS Bernardo BarRoso \\ WLAdiRSOn Ronny da Silva Cardoso \\ Universidade do Estado do Pará (UEPA), Belém, Pará, Brasil \\ Marcelo Ribeiro de Mesquita \\ Universidade Federal do Pará (UFPA), Belém, Pará, Brasil
}

\begin{abstract}
Resumo: O presente artigo investiga a influência da educação, especificamente da educação física com pessoas transexuais, em Belém do Pará. Tem como objetivo descrever as contribuições positivas, negativas ou indiferentes da educação e da educação física, na vida social de pessoas transexuais. Caracteriza-se como uma pesquisa de teor qualitativo, utilizando-se de pesquisa de campo junto com entrevistas semiestruturadas com pessoas transexuais que já concluíram o ensino básico. Os dados foram analisados por meio de análise de conteúdo. Os resultados demonstraram que a educação básica e a educação física, em grande parte, ainda se caracterizam como experiências segregadoras e de grande impacto para estas pessoas, tendo como conclusão do entrevistador e dos interlocutores que a melhor forma para se desenvolver os conteúdos seria por meio de aulas mistas, com estudo mais aberto quanto a gênero e sexualidade.
\end{abstract}

Palavras-chave: Gênero. Transexual. Escola. Educação Física.

INTRODUÇÃO

Este trabalho busca compreender os impactos sociais que a educação básica, com foco na educação física, causou em pessoas transexuais da cidade de Belém do Pará. Essas pessoas têm dentro de si um entendimento diferente quanto ao feminino e ao masculino estereotipado pela sociedade atual, que é repleta de pré-conceitos para cada pessoa - sejam eles de gênero, classe, cor, sexualidade, entre outros. Pode-se acompanhar o desenvolvimento desses conceitos ao mesmo tempo em que se acompanha a construção da mentalidade da sociedade e das pessoas que nela se inserem.

Justamente por essa construção da mentalidade social e individual é que não podemos deixar de lembrar o papel da escola nesse ínterim, pois se pode considerar que esse é o lugar onde as crianças passam grande parte do seu tempo, devendo assim haver um trato mais cuidadoso quanto à disseminação de estereótipos segregadores. No entanto, "a escola tornou-se [...] um espaço em que rotineiramente circulam preconceitos 
que colocam em movimento discriminações de diversas ordens" (JUNQUEIRA, 2012, p. 04).

Nessa perspectiva é que se lançou o seguinte problema de pesquisa: Como a educação física atual, com toda sua carga histórica de segregação de gênero no âmbito da corporeidade, influenciou na vida social de pessoas que se identificam como transexuais? Desse problema emerge um conjunto de questões que norteiam o problema de pesquisa: 1. Qual o efeito social da educação, com foco na educação física, em pessoas transexuais? 2. A educação física atual e o trato dos/das professores/as de educação física quanto às aulas, influenciou de forma positiva, negativa ou nula em suas vidas? 3. Existe algum caminho a ser trilhado para que esta realidade possa mudar?

A pesquisa tem como justificativa a experiência que os pesquisadores tiveram e ainda têm dentro do movimento LGBT (Lésbicas, Gays, Bissexuais e Transgêneros), com base em uma das pautas mais imediatas que foram encontradas dentro da militância: a educação. Por meio dessas pautas, do movimento, das vivências e das buscas de referências, percebe-se o quão escasso é o tema da transexualidade dentro da Educação Física. Poucas são as pesquisas encontradas, tendo um arcabouço de referências muito raso quanto à transexualidade dentro do âmbito escolar na educação física.

Por fim, deve-se lembrar a importância desta pesquisa para sociedade atual, visto que é de grande mérito que a sexualidade e o gênero sejam cada vez mais explicados por nós professores, e compreendida pelos alunos para que esses, agora jovens, não precisem passar por certos sofrimentos e embates que outros, anos atrás, foram obrigados a sustentar.

Diante dessa realidade, o estudo que analisou a relação entre educação física e transexualidade se justifica, visto que a educação física ainda é um terreno cercado de preconceitos e discriminações, considerando que muito se caracteriza os movimentos corporais como práticas sexistas e discriminatórias, em que alguns esportes ou práticas corporais são vistos exclusivamente para um determinado sexo.

Dessa forma, o objetivo geral desta pesquisa é o de descrever as contribuições positivas, negativas ou indiferentes da educação, com foco na educação física, na vida social de pessoas transexuais. E possui como objetivos específicos os que seguem: 1. Descrever o papel que a educação, com foco na educação física, desempenhou no processo de escolarização de pessoas transexuais no ensino básico; 2 . Compreender a visão de pessoas transexuais quanto à educação física escolar e aos impactos que esta prática causou nelas. 3. Apontar um futuro caminho para que a educação física não continue sendo um campo tão segregador.

A pesquisa assume o teor qualitativo pois, como afirma Oliveira (2008), o pesquisador não deve ser um observador ausente, para que assim este possa interpretar, vivenciar e, em alguns casos, participar ativamente da pesquisa. Para Gerhardt e Silveira (2009, p. 31), "a pesquisa qualitativa não se preocupa com representatividade numérica, mas, sim, com o aprofundamento da compreensão de um grupo social, de uma organização, etc.". Esse tipo de pesquisa foi escolhido devido à aproximação do tema deste trabalho com a base pessoal, social, militante e acadêmica dos pesquisadores, "isto porque, existe a necessidade de empatia para que o entrevistado se disponha a responder corretamente as questões" (OLIVEIRA, 2008, p. 108). 
A pesquisa de campo partiu do consentimento de um grupo de pessoas transexuais maiores de idade residentes em Belém do Pará, podendo assim ser coletadas as experiências, inquietações e relatos dessas pessoas quanto à educação básica escolar e à educação física. Foi adotado o modelo de entrevista semiestruturada, dando liberdade para o entrevistado falar sobre o tema, abrir adendos, questionar e complementar a pesquisa, tendo como percurso orientador perguntas que busquem responder 0 questionamento principal da pesquisa proposta.

A análise de dados deu-se com as conclusões que puderam ser tomadas a partir das entrevistas coletadas, argumentando com outros autores para conseguir expor como a educação básica, principalmente a educação física influenciou - de forma positiva, negativa ou nula - na vida dos interlocutores que contribuíram para o desenvolvimento desta pesquisa.

\section{1- ENTENDENDO O(S) GÊNERO(S) E A SEXUALIDADE}

É de suma importância pontuar, primeiramente, a diferença entre sexualidade e gênero, já que ainda hoje, para muitas pessoas, uma se confunde com a outra.

Segundo Wilm (2016, p. 1), orientação sexual é "[...] para onde nosso desejo sexual está apontando, se é para homens, mulheres, ambos ou nenhum.".

Podemos considerar também o documento de princípios de Yogyakarta, este que trata de forma ampla as normas de direitos humanos e as suas aplicações quanto à questão da orientação sexual e identidade de gênero. Encontramos a distinção de sexualidade e gênero, e segundo o documento, orientação sexual é "ter uma profunda atração emocional, afetiva ou sexual por indivíduos de gênero diferente, do mesmo gênero ou de mais de um gênero, assim como ter relações intimas e sexuais com essas pessoas" (PRINCÍPIOS DE YOGYAKARTA, 2007, p. 7).

Quanto à sexualidade, existem inúmeras formas que esta se apresenta e que podem ser citadas. Segundo a Cartilha Diversidade Sexual e Cidadania LGBT (2014, p.5), existem orientações sexuais majoritárias, como:

- $\quad$ Heterossexualidade - "Pessoa que se sente atraída afetiva e/ou sexualmente por pessoas do sexo/gênero oposto".

- Homossexualidade - "Pessoa que se sente atraída afetiva e/ou sexualmente por pessoas do mesmo sexo/gênero", incluem-se aqui lésbicas e gays.

- $\quad$ Bissexualidade - "Pessoa que se sente atraída afetiva e/ou sexualmente por pessoas de ambos os sexos/gêneros".

Para além destas, podemos citar também:

- Panssexualidade - Pessoas que sentem atração por outras pessoas, independente do gênero, sexualidade, genital, etc.

- Assexualidade - Pessoas que não sentem atração por nenhum dos sexos/gêneros.

Já identidade de gênero, para Wilm (2016, p. 2) “[...] refere-se ao gênero que reconhecemos pertencer (homens, mulheres, outros)". E no documento Yogyakarta pode-se achar a conceituação de identidade de gênero, que seria: 
[...] a experiência interna e individual do gênero de cada pessoa, que pode ou não corresponder ao sexo atribuído no nascimento, incluindo o senso pessoal de corpo (que pode envolver, por livre escolha, modificação de aparência ou função corporal por meios médicos e cirúrgicos ou outros), e outras expressões de gênero, inclusive vestimenta, modo de falar e maneirismos. (PRINCÍPIOS DE YOGYAKARTA, 2007, p. 7).

Tendo essas diferenças quanto a gênero e sexualidade em mente, pode-se prosseguir para o segundo esclarecimento que deve ser feito: $O$ que é uma pessoa transgênero e o que é uma pessoa cisgênero?

Para Jesus (2012, p.16), uma pessoa cisgênero é aquela que "[...] se identifica com o gênero que Ihes foi atribuído quando ao nascimento", ou seja, é a pessoa que se sente a vontade com o gênero que lhe foi atribuído por médicos, família e sociedade.

E segundo Jayme (2004), os transgêneros são pessoas que modificam a visão binária de masculino e feminino, que usam do seu próprio corpo como forma máxima de expressão social, cultural e pessoal, "o termo transgênero é utilizado para reunir todas essas categorias [...], mas mantendo suas diferenças" (JAYME, 2004, p. 3). Souza e Bernardo (2014) afirmam também que transgêneros são aqueles que contêm em si a certeza de que não irão "[...] poder corresponder às expectativas definidas socialmente para o seu sexo anatômico, identificando-se com os elementos tidos como do sexo oposto ao seu e submetendo-se a tratamentos cirúrgicos e/ou hormonais para adequar seu corpo à sua condição psicológica" (SOUZA; BERNARDO, 2014, p. 159).

Jesus (2012) conceitua todas essas identidades trans como "Transgener(al)idades", sendo estas Travestis - "[...] pessoas que vivenciam papéis de gênero feminino, mas não se reconhecem como homens ou mulheres, mas como membros de um terceiro gênero ou de um não-gênero." (JESUS, 2012, p. 16).

Contudo, esta definição que Jesus traz se mostra errônea, já que segundo a Cartilha da Diversidade do Estado do Pará (2017), mulheres travestis se identificam como "pessoas que nascem como sexo macho, mas que tem sua identidade de gênero oposta ao seu sexo biológico, assumindo o papel de gênero diferente daquele imposto pela sociedade." (2017, p.12). O termo travesti só é encontrado no Brasil, e é assumido por estas mulheres como sinônimo de luta e resistência, visto que é delas o grande mérito de ter iniciado o processo de reconhecimento das diversas identidades de gênero no Brasil. Seguindo o estudo de Jesus (2012, p.16):

Crossdresses - são homens heterossexuais que "[...] têm satisfação emocional ou sexual momentânea em se vestirem como mulheres [...]", estes "[...] sentem-se como pertencentes ao gênero que lhes foi atribuído ao nascimento, e não se consideram travestis.".

- Drag-Queen/Drag-king/Transformistas - são artistas que "[...] fazem uso da feminilidade \{masculinidade ou ambas\} estereotipada e exacerbada em apresentações [...]". Estes têm essa perspectiva de gênero voltada unicamente para o entretenimento e apresentações.

Transexuais - A autora identifica diversas formas de se definir o que é transexual que vão desde clínicas e biológicas até as sociais. Para ela, "Mulher transexual é toda pessoa que reivindica o reconhecimento social e legal como mulher" assim como "homem transexual 
é toda pessoa que reivindica o reconhecimento social e legal como homem".

Os interlocutores presentes nesta pesquisa se identificam como pessoas transexuais, militantes e paraenses, sendo estes: três mulheres trans e três homens trans, entre 20 e 30 anos. Os Gráficos 1 e 2 mostram as idades em que os sujeitos trans desta pesquisa, descobriram o que era ser trans e assumiram para a sociedade a identificação com o gênero oposto àquele que lhes foi atribuído ao nascimento.

Gráfico 1: Idades dos sujeitos quando assumiram ser trans

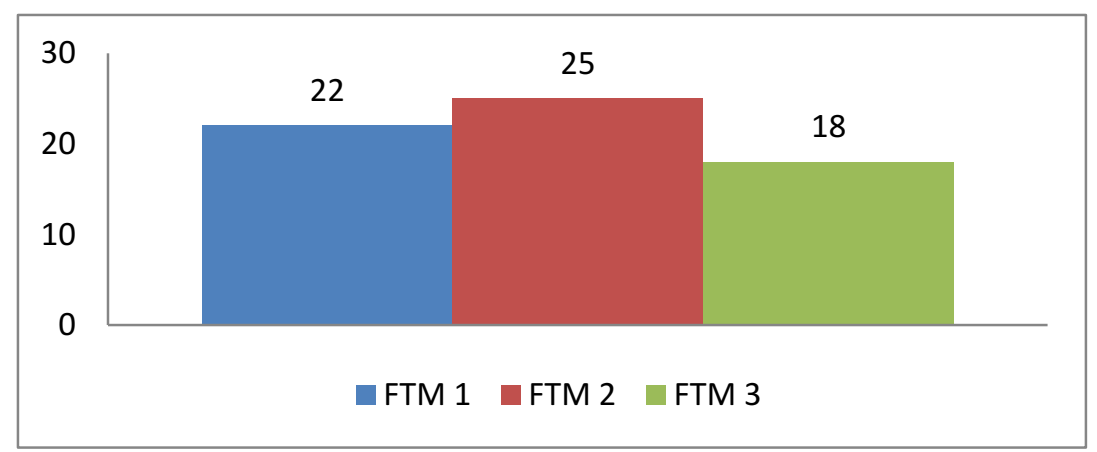

Fonte: Diálogo com as pessoas que contribuíram para esta pesquisa.

Gráfico 2: Idades dos sujeitos quando assumiram ser trans

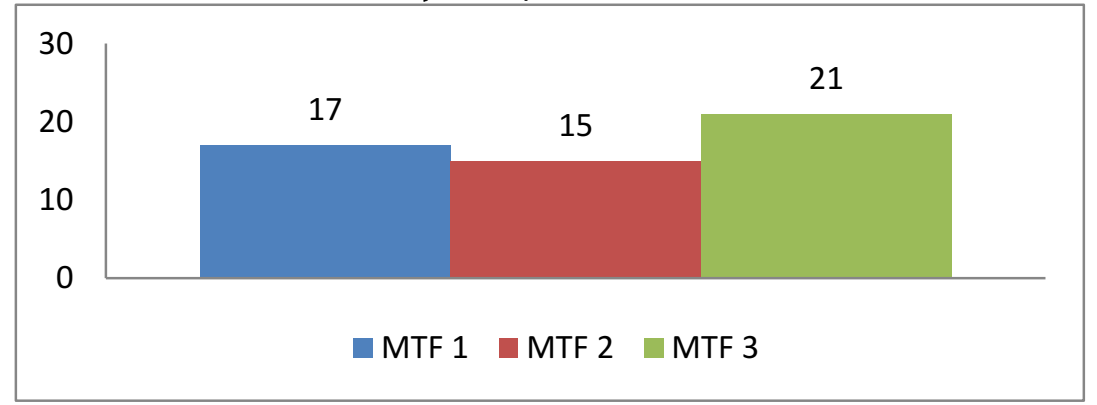

Fonte: Diálogo com as pessoas que contribuíram para esta pesquisa.

Serão utilizados nomes fictícios para a identificação dos interlocutores desta pesquisa, pois segundo Freitas e Silveira (2008), "ao conquistar a adesão do sujeito, o pesquisador recebe $o$ encargo de resguardar a privacidade deste. $O$ compromisso do pesquisador com o sigilo é uma condição sine qua non para que possa realizar pesquisa com humanos" (FREITAS; SILVEIRA. 2008 p. 42).

Para isto, serão utilizados, nomes de divindades das mitologias ao redor do mundo que simbolizam de alguma forma a cultura LGBT em suas épocas e culturas. Assim, os interlocutores desta pesquisa serão identificados da seguinte maneira:

Dionísio, que irá representar o Interlocutor 1, é o grande patrono dos intersexuais e travestis na Grécia, é visto como o Deus dos vinhedos e das grandes orgias sexuais, seus rituais eram feitos com muita dança, música e bebidas. 
Xochipilli, que irá representar o interlocutor 2, era o príncipe asteca das flores, da beleza, música, dança, arte, bem estar, prazeres e fertilidade. Padroeiro dos homossexuais e dos prostitutos masculinos. É uma divindade que assumia tanto aspectos masculinos quanto aspectos femininos.

Hu Tian Bao, que irá representar o interlocutor 3, é conhecido como o "deus coelho" na mitologia chinesa, este, quando humano, era um oficial que se apaixonou por um inspetor imperial. Na época, Hu Tian Bao foi espancado até a morte e após isso, tornou-se uma divindade, sendo reverenciado por devotos homossexuais, como o Deus Patrono do Amor Homossexual.

Ishtar, que irá representar a interlocutora 4, é vista em alguns momentos como a deusa babilônica do amor e da fertilidade e em outros momentos como a deusa da guerra, da chuva e do trovão. Após ser salva do submundo por uma criatura macho-fêmea denominada de Asushnmir, criada por Enki, deus da lua, ofereceu abrigo em seu templo a todos os semelhantes de Asushnmir que viessem a nascer. Na Mesopotâmia, o culto a essa deusa é frequentemente associado a eunucos, andrógenos, pessoas sexualmente ambivalentes, intersexuais e travestis.

Bahuchara, que irá representar a interlocutora 5, é uma deusa Hindu venerada pelas "hijras", que para os hindus, não são homens nem mulheres, mas sim, pertencentes a um terceiro sexo. São em sua maioria, indivíduos do sexo anatômico masculino que passam por um processo cirúrgico para a retirada do pênis e dos testículos em oferecimento à deusa. Alguns dizem se sentir completos apenas após a cirurgia.

Kuan Ying, que irá representar a interlocutora 6, é uma divindade da mitologia oriental, que reflete em seus mitos a fluidez de seu gênero e sua sexualidade, podendo aparecer em forma de um belo rapaz, que seduz velhos monges a fim de levá-los à iluminação, como em forma de uma formosa moça, que luta e engaja-se em atividades sexuais para salvar seus fiéis.

Pode-se perceber assim que a cultura LGBT não veio surgindo junto com os tempos atuais, mas que na verdade ela sempre esteve presente, desde as culturas mais antigas, até as mais contemporâneas. Sempre existiram deuses que em algum momento demonstraram fluidez quanto ao seu gênero e sexualidade, e acreditando que as divindades são resultado da fé de seus devotos, entende-se que sempre existiram pessoas com "fluidez" sexual e de gênero ao redor do mundo, em todas as culturas e em todas as épocas.

\section{2 - ENTRE GENITAIS, MANEIRISMOS E ESTEREÓTIPOS}

A primeira coisa que comecei a fazer foi deixar meu cabelo crescer, depois começar a usar maquiagem, depois usar short curto, usar roupa de menina (Ishtar).

Eu lembro de quando eu era bem pequeno, acho que tinha uns 7 ou 8 anos, eu lembro que eu sempre brincava de casinha e eu sempre era o pai, eu sempre queria ser o pai (Dionísio).

Quando se precisa lidar com os estereótipos para o feminino e o masculino, muito se pode falar quanto à construção sócio-histórica pré-estabelecida nas crianças que 
nascem, seja nessa ou em outra época. A carga histórica da sua cultura, do país, do modelo de sociedade vigente recai sobre a construção da mentalidade das crianças.

O gênero e o papel desse gênero é, segundo autores como Judith Butler (2003), uma construção social estabelecida anteriormente pela visão biológica binária de masculino e de feminino, "Supondo por um momento que a estabilidade do sexo biológico não decorre daí que a construção de 'homens' aplique-se exclusivamente a corpos masculinos, ou que o termo 'mulheres' interprete somente corpos femininos". (BUTLER, 2003, p. 24).

Tende-se a instaurar nos corpos biologicamente ditos femininos o comportamento mais passivo, complacente, dócil e calmo, já nos corpos biologicamente ditos masculinos, a consciência agressiva, ativa, dominadora, conquistadora, e esse "[...] modo como homens e mulheres se comportam em sociedade corresponde a um intenso aprendizado sociocultural que nos ensina a agir conforme as prescrições de cada gênero" (BARRETO; ARAÚJO; PEREIRA, 2009, p. 40).

Esses papéis de gênero são vistos nitidamente até nos próprios corpos transgressores dessa dicotomia biológica, os corpos trans. Quando Ishtar diz ter começado a transição do corpo masculino para o feminino com o uso mais constante de elementos do mundo "feminino", como maquiagem, roupas curtas e cabelo longo, podemos perceber como a visão social dos maneirismos influencia em grande parte essa construção da consciência corporal e social própria.

Por conta desses papeis de gênero estabelecidos pela sociedade, o corpo, seja este transitivo ou não, deixa de ser reconhecido apenas como um conjunto de ossos, músculos, órgãos, impulsos nervosos, vísceras e nervos. Quando se descobre a genital pertencente àquele ser humano prestes a nascer, o corpo passa a ser um objeto de intervenção social, sendo assim "O corpo é também a roupa e os acessórios que o adornam, a imagem que dele produz, as máquinas que nele se acoplam, os sentidos que nele se incorporam, os silêncios que por ele falam, os vestígios que nele se exibem, a educação de seus gestos" (GOELLNER, 2003, p. 29).

Muitos dos interlocutores desta pesquisa já sentiam incomodo com o corpo, mesmo antes de conhecer a transexualidade, como aponta o Gráfico 3.

Gráfico 3: Incômodo com o corpo na infância e adolescência

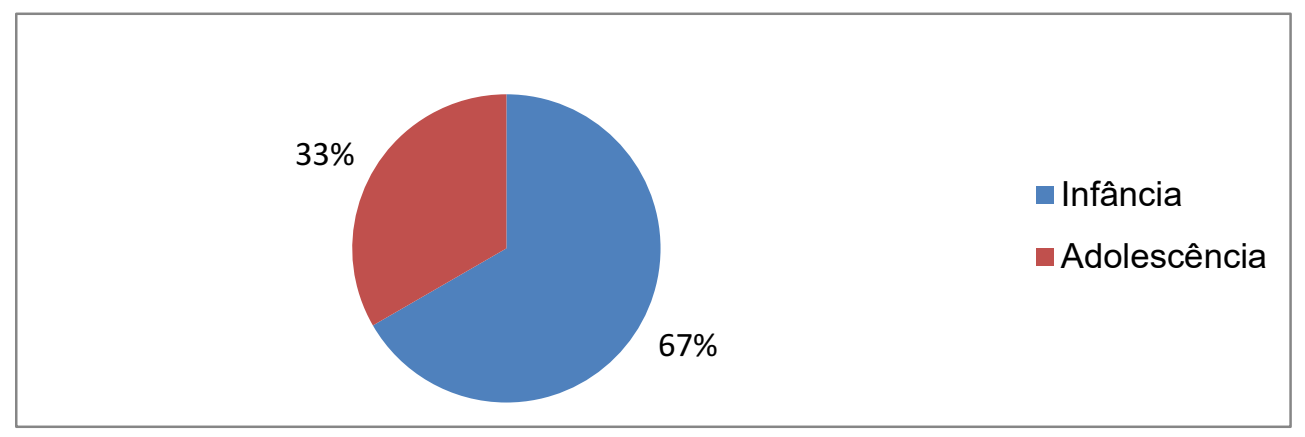

Fonte: Diálogo com as pessoas que contribuíram para esta pesquisa. 
Estes dados demonstram que, $67 \%$ dos interlocutores já sentiam incômodo com o próprio corpo na infância, e já não se identificavam com o papel de gênero que lhe foi atribuído conforme apontam algumas falas:

[...] a maneira que eu me sentia diferente, isso vem, que eu me lembre, desde os meus sete anos. (Ishtar).

Eu lembro de quando eu era bem pequeno, acho que tinha uns 7 ou 8 anos, eu lembro que eu sempre brincava de casinha e eu sempre era o pai [...] Eu sempre soube o que eu era, só que eu não tinha a noção da palavra e nem tinha a noção do que poderia acontecer de fato depois que eu começasse a transicionar. (Dionísio)

De acordo com os dados coletados nesse gráfico, também foi possível observar que $33 \%$ dos interlocutores, tanto entre os homens trans quanto entre as mulheres trans, não sentiam um incômodo muito latente em suas infâncias, mas passaram a sentir isto na adolescência, como nos aponta Hu Tian Bao:

[...] eu tive vários conflitos com meu corpo, eu não sabia o que era, eu cheguei a ter bulimia durante a minha pré-adolescência e durante a adolescência, e eu passei por vários conflitos, eu não sabia o que tinha de errado comigo.

Esses conflitos são semelhantes nas falas de todos os interlocutores, o sentimento de não pertencimento ao próprio corpo é algo que aflige essa população. Algumas pessoas trans, ao começarem a transição, passam primeiro pelo processo de não aceitação da transexualidade, vindo à tona também a vergonha do que está acontecendo, justamente pela imposição social que está sendo quebrada.

[...] eu me inibia de sair na rua, pelo o que as pessoas iriam falar e quando eu ia na rua eu era muito acuada, por que as pessoas olhavam pra mim e eu ficava com muita vergonha, por que eu não sabia o que elas estavam falando de mim, o que elas pensavam de mim. (Bahuchara).

[...] principio eu não me aceitava enquanto pessoa trans, por conta de toda a criação que eu tive, eu achava que isso era loucura, que talvez isso não existisse. (Xochipilli)

Esses modelos são colocados desde o nascimento, onde alguns valores como heterossexualidade, cristianismo, dominação masculina por sobre a feminina, entre outros, são interiorizados dentro dos indivíduos por inúmeras instituições presentes no desenvolvimento pessoal e social de todos (FRANCO, 2016). Sendo assim, "aprendemos a viver o gênero e a sexualidade na cultura, através dos discursos repetidos da mídia, da igreja, da ciência, das leis e também, contemporaneamente, através dos discursos dos movimentos sociais e dos múltiplos dispositivos tecnológicos" (LOURO; 2008, p. 22-23).

Justamente por isso é tão difícil para a sociedade, mesmo após a pseudo aceitação da transexualidade, entender e respeitar a transexualidade homossexual/ bissexual/ pansexual, visto que para muitos, o gênero e a sexualidade andam de mãos dadas a todo o momento, e por isso um homem trans - que em alguns casos antes da 
transição se identificava como mulher lésbica, e após a transição se identifica como homem hétero - é compreendido "mais rapidamente", já que mantém o comportamento aceitável para o gênero masculino.

Assim como uma mulher trans - que igualmente em alguns casos, antes da transição se identificava como homem gay, e após a transição se identifica como mulher hétero - também é compreendida mais "rapidamente", visto que também segue o padrão social aceitável para o gênero feminino. Por isso, um homem trans gay ou uma mulher trans lésbica, ou ambos bissexuais/panssexuais sofrem retaliações multiplicadas, por fugir tanto do padrão de gênero quanto de sexualidade.

Grande parte dessa vivência de gênero se passa, também, dentro do ambiente escolar, onde a criança/adolescente passa cerca de metade dos seus dias. Logo, "educadores e educadoras têm a possibilidade de reforçar preconceitos e estereótipos de gênero, caso tenham a atuação pouco reflexiva sobre as classificações morais existentes entre atributos masculinos e femininos" (BARRETO; ARAÚJO; PEREIRA, 2009, p. 51).

\section{3 - IMPORTÂNCIA DE SE DISCUTIR GÊNERO E SEXUALIDADE NA ESCOLA}

A educação básica escolar brasileira é um ambiente com inúmeros padrões a serem seguidos, padrões estes que são reflexo dos conceitos estabelecidos pela nossa sociedade desde a colonização: "[...] brancos, machos, eurocêntricos, colonialistas, burgueses, cristãos, ilustrados e heterossexuais" (VEIGA-NETO; NOGUEIRA apud FRANCO, p. 48), e isso é visto tanto nas salas de aulas quanto nas quadras esportivas. Junqueira (2012), afirma que estes padrões não fazem parte apenas do "currículo oculto" da escola, mas que também estão presentes no "currículo formal" escolar, visto que este se dá "por meio da produção de regras e de padrões da verdade, da seleção, organização, hierarquização e avaliação do que é definido como conhecimento/conteúdo escolar" (JUNQUEIRA, 2012, p. 02)

É possível perceber, diariamente, a segregação de gênero e sexualidade, imposta tanto por professores quanto pelos alunos entre si. Algumas vezes, essa segregação é velada, encoberta pelo título de brincadeira, mas também pode vir de forma direta, com palavras de ódio, atitudes e reações lesivas. É possível perceber isso quando:

[...] eu passava pelos corredores da escola e eu servia muito de chacota, os meninos tiravam muita onda com a minha cara, os meninos tipo zoavam muito, de chegar dentro da sala e minhas coisas estarem mexidas, só pra eu ficar estressada e brigar[...] eu sofria muito, por conta dessas brincadeirinhas, dessas chacotas e eu passava no corredor e os meninos ficavam gritando (Bahuchara).

Os interlocutores desta pesquisa frequentaram escolas diferentes e em momentos diferentes, como aponta o gráfico 4: 
Gráfico 4: Escolas dos interlocutores

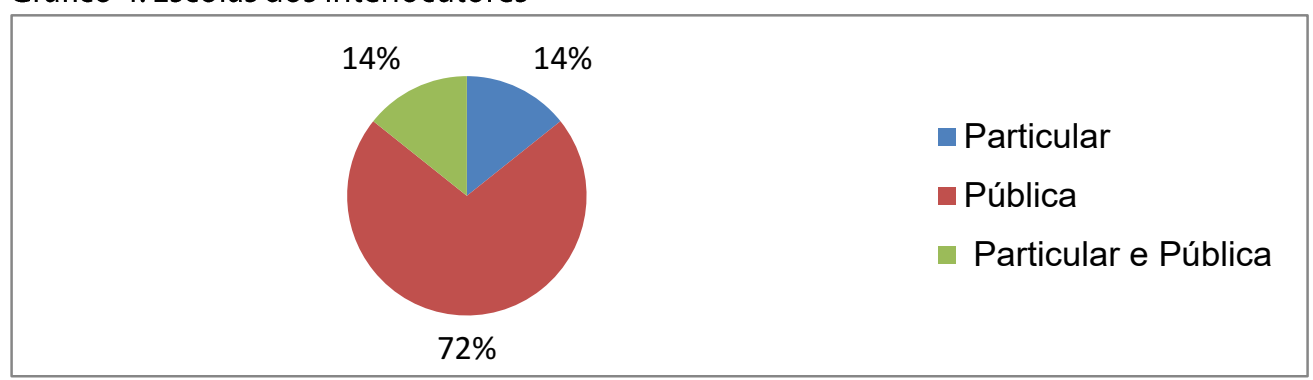

Fonte: Diálogo com as pessoas que contribuíram para esta pesquisa.

Dentre os interlocutores, $72 \%$ estudaram unicamente em escola pública, $14 \%$ estudaram unicamente em escola particular e $14 \%$ estudaram em ambas. Nos relatos onde são apontadas as práticas para que houvesse certa liberdade de gênero e sexualidade, a escola particular se sobrepõe, visto que, de acordo com os relatos da interlocutora que estudou a vida toda em escola particular, nesta os alunos tinham a possibilidade de estudar artes, interpretar peças e ter melhores experiências sociais proporcionadas pela escola.

E o \{nome da escola\} é uma escola muito artística, tem dança, peça e eu acho que tive muita sorte por passar por uma escola que é muito artística, até por que o diretor da escola é gay, então faz com que a escola seja mais aberta, quanto à questão da arte e da cultura. Toda escola deveria ter cultura, se interessar pela arte, e a gente tinha tudo, dança, pintura, encenação (Ishtar).

Entretanto, em um dos relatos, especificamente o do interlocutor que frequentara ambas as escolas, sua vivência na escola particular foi repleta de conflitos, visto que esta escola era de doutrina religiosa, fazendo com que a liberdade de gênero e sexualidade só fosse aceita depois de inúmeros conflitos e discussões.

[...] Eu fui pra escola particular, e eu acho que no ensino médio já ficou mais complicado, por que eu fui pra uma escola adventista, e já ficou bem mais complicado [...] Diretoria eu sempre tive problema, por que eu era muito doido saca? Eu sempre ia pra lá, eu sempre queria que a galera me respeitasse e eu ia, fazia minhas ondas e eu fui expulso de três escolas por causa disso, mas tipo era ruim né por que infelizmente, eu não sabia o que estava acontecendo comigo, mas agora eu consigo entender (Dionísio).

Conforme destaca Louro (1999, p. 19), "as marcas que nos fazem lembrar [...] dessas instituições têm a ver com as formas como construímos nossas identidades sociais [...]" e é para essas instituições que podemos atribuir o papel fundamental de orientador na construção ou desconstrução de inúmeros preconceitos instaurados pela sociedade, dado que dentro da escola, para além de um espaço para aprender matérias letivas, aprendemos e ensinamos modos de pensar, agir, conhecer, explorar e difundir os ideais ali construídos. Assim, "O papel da escola neste mundo que se transforma, deve estar equilibrado entre uma função sistêmica de preparar cidadãos tanto para desenvolver 
suas qualidades como para a vida em sociedade" (PIRES, 2013, p. 30). Bem como criar "[...] condições para que os indivíduos possam agir em seu meio e tornar-se mais atuantes na sociedade, através de uma forma mais crítica e menos alienadora, passando a serem sujeitos conscientes de suas ações" (PIRES, 2013, p. 32).

\section{4 - EDUCAÇÃo FÍSICA: PRÁTICAS E GÊNERO}

Da mesma forma que a educação básica geral, quando se trata da educação física é possível destacar os pré-conceitos adquiridos historicamente acerca dos esportes, da dança e de outras manifestações corporais. Quanto a isso, Daolio (1995) dá um exemplo muito bem encaixado: "os meninos brasileiros, como se diz correntemente, 'nascerem sabendo jogar futebol'. De forma contrária, ainda segundo o senso comum, podemos dizer que as meninas brasileiras, além de não nascerem sabendo, nunca conseguem aprender a jogar futebol" (DAOLIO, 1995, p. 40).

Na prática esportista ou de movimento corporal, os papeis pré-estabelecidos para homens e mulheres agem tanto de forma explicita, quando vislumbramos por exemplo o cenário mundial da dança, com pouca representatividade masculina, ou no futebol, em que as seleções femininas pouco têm importância para a mídia, e por consequência, para a sociedade que move e fomenta o esporte, quanto implícitas, quando as insinuações e brincadeiras se iniciam para um garoto que não sente interesse pelo futebol ou quer dançar na escola e para a garota que não se sente à vontade dançando, e sim praticando esportes ditos "masculinos".

[...] o professor sempre me colocava pra jogar futebol com os meninos, né, mas na verdade eu nunca gostei de futebol. (Bahuchara)

[...] mas as vezes me deixava triste também pelo fato de tipo ouvir aquilo "ah, nossa, tu é muito boa pra uma mulher, parece homem" as pessoas não conseguiam me enxergar da forma que eu queria que elas me enxergassem de fato. (Xochipilli)

O futebol, um dos maiores ícones atuais da educação física, esporte e cultura, socialmente mantém até hoje a visão de que é esporte de prática exclusiva masculina, "a virilidade virtuosa do esporte é frequentemente ressaltada pela sentença 'futebol é coisa pra macho'" (FRANZINI, 2005, p. 316). Não apenas o futebol em si, mas também muitos outros esportes de contato, como o basquete ou as lutas.

Entretanto, muitas escolas deixam de adotar esse tipo de aula, dando preferência para a prática da educação física separada. Estas práticas podem contribuir para a disseminação do preconceito de gênero e por consequência da LGBTfobia. Dentre pessoas que contribuíram para a elaboração desta pesquisa, $83 \%$ tiveram a educação física separada e $17 \%$ mista, como aponta o gráfico 9. 


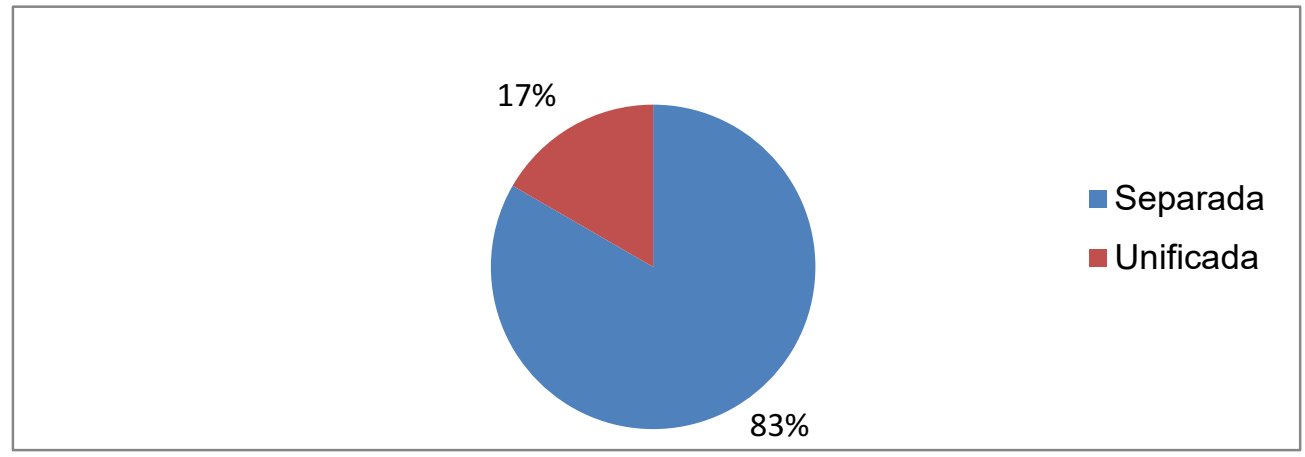

Fonte: Diálogo com as pessoas que contribuíram para esta pesquisa.

O preconceito de gênero dentro da educação física pode acontecer ocorrer tanto de forma mais aberta, como em momentos que os gêneros são segregados por horários, como de uma forma mais velada, usando de artifícios como "esportes específicos para determinado sexo", como nos mostra a fala dos interlocutores:

[...] e eu sempre falava "professor, deixa eu jogar queimada com as meninas!" e ele dizia que não a queimada é só pras meninas e futebol é só pros meninos (Bahuchara).

[...] o que eu lembro da educação física, mudou de professor pra professor, e a maioria dos professores separava meninos e meninas pra educação física, os meninos jogavam futebol, as meninas ficavam na ginastica, ai na outra escola, os meninos continuavam no futebol e as meninas ficavam no vôlei (Xochipilli).

Essas práticas impactaram de forma negativa na vida das pessoas transexuais que contribuíram para a elaboração desta pesquisa, visto que, quando a sua identificação com o gênero oposto lhes era negada, estes passavam a se excluir da educação física, como podemos perceber na fala abaixo:

[...] eu ficava sem fazer nenhuma atividade física na escola, por essa exclusão de gênero, meninas pra um lado e meninos para o outro, e como eu não me identificava com o jogo que os meninos estavam, eu simplesmente me excluía e ficava só olhando, e quando era prova, eu falava "professor, passe um trabalho pra mim, por que na verdade, eu não to me sentindo bem", enfim, eu sempre inventava alguma desculpa (Bahuchara).

É importante citar que 17\% dos interlocutores afirmou ter uma educação física mista, onde homens e mulheres interagiam entre si e faziam práticas iguais, e juntamente com isso os impactos positivos que esta prática ocasionou, como podemos constatar nos excertos abaixo:

[...] educação física era a matéria que eu gostava mais, por que a gente fazia esporte, corria, e eu gostava muito de fazer essas coisas, e principalmente por que a gente brincava e tal

[...] eu lembro que no tempo também a gente juntava com as outras turmas, era menino 
e menina e não tinha uniforme diferente, o uniforme era padrão mesmo, foi a melhor escola da minha vida, com a melhor educação física (Hu Tian Bao).

[...] a educação física lá da escola era unida, até por que tinham poucos alunos. Então, não tinha como separar em homem e mulher. A gente jogava todos juntos e isso era bom, por que eu não precisava ficar sempre jogando com os meninos (Kuan Ying).

A educação física segregada se mostra, portanto, ser uma das maiores causadoras de impactos negativos dentre os interlocutores, visto que "[...] as aulas separadas entre meninos e meninas não apenas operam uma separação física entre dois grupos, mas são espaços que ensinam masculinidade(s) e feminilidade(s), sobre o que é adequado para meninos e meninas na Educação Física escolar" (DORNELLES, 2006, p. 6).

Neste meio, pessoas transexuais eram obrigadas a participar de uma prática corporal condizente com o gênero ao qual não se identificavam, tal como foi constatado nos diálogos com os interlocutores, em que uma das maiores implicações para a não participação da prática da educação física era o uso dos uniformes diferenciados para homens e mulheres como nos aponta a fala:

[...] então eu sempre tive problema com direção por causa disso [...] por que a direção dizia "não, tu não pode vir com esse short senão tu não vai fazer educação física", por que eu realmente gostava de educação física, [...] mas eu tinha problemas principalmente por causa da vestimenta, que os meninos sempre usam bermudão né, aquelas coisas mais largas, e as meninas usam os shorts mais curtos, apertados, e eu queria usar o short curto e apertado, e a direção não deixava [...] mesmo eu conversando com professor [...] eles chegavam comigo e falavam que eu não podia fazer porque estava com tal uniforme, ai eu falava "tá, sem problema nenhum, eu não faço, mas eu não vou vim com a roupa que eles querem que eu venha" (Ishtar).

Dornelles e Fraga (2009) afirmam, entretanto, que apenas a aplicação das aulas mistas não é suficiente para que o respeito quanto às questões de gênero se torne presente e de fácil entendimento para os alunos, é preciso também a aplicação da coeducação, onde professores, alunos, corpo docente e corpo administrativo escolar poderão “[...] problematizar as relações de gênero, objetivando uma compreensão da construção cultural das diferentes posições de poder ocupadas pelo feminino em relação ao masculino e vice-versa na nossa sociedade" (DORNELLES;FRAGA, 2009, p. 147).

\section{CONSIDERAÇÕES FINAIS}

[...] eu acredito assim, que a atitude que ele deveria tomar era perguntar pros alunos o que eles gostariam, tipo, olha tem futebol e tem jogo de queimada, qual vocês querem? Querem pra fazer educação física, entendeu? Acho que sempre eles deveriam perguntar, entende? Não chegar e impor, não, mas perguntar, qual você se sente melhor? Jogando futebol ou jogando queimada? (Bahuchara)

[...] acho que a primeira coisa que eu faria e que todos deveriam fazer é tirar essa diferença de que meninos jogam futebol e meninas jogam queimada, e juntar todo mundo e que todos sejam felizes (Hu Tian Bao). 
Todos os interlocutores que contribuíram para o desenvolvimento desta pesquisa, ao serem questionados sobre o que mudariam quanto à prática da educação física, com tom esperançoso recomendaram a não segregação da educação, em especial da educação física, assim como a aproximação de todos os alunos, mesmo que estes sejam diferentes em suas raças, sexualidades, gêneros, tamanhos, credos, fenótipos e genótipos.

Quando, por preconceitos explícitos ou velados, um professor deixa de compreender o aluno, comete o maior dos erros: o de não se deixar aprender. Todos são capazes de ensinar e de continuar aprendendo, mesmo que este aprendizado venha com algo novo e que muitas vezes se mostre assustador. Todos devem aprender a aprender com os alunos, com a comunidade, com os colegas de trabalho e todas as realidades que nos cercam.

Sendo assim, o professor se torna um dos grandes responsáveis pela aproximação da comunidade com a escola, fazendo com que o ambiente escolar deixe de ser um ambiente hostil para algumas minorias e passe a ser um local de acolhimento, cuidado e segurança.

Concluímos, então, que a educação básica e a educação física têm uma grande capacidade de agregar e ajudar inúmeras pessoas, não apenas do meio LGBT mas de qualquer meio social.

Artigo recebido em: 23/08/2017 Aprovado para publicação em: 18/12/2017

\section{SCHOOL PHYSICAL EDUCATION: THE SOCIAL IMPACTS IN THE LIFE OF TRANSEXUAL PEOPLE IN BELÉM DO PARÁ}

ABSTRACT: This article investigates the influence of education, specifically the physical education with transgender people of Belém do Pará. Aims to describe the positive, negative or indifferent contributions of education and physical education, before social life of transgender people. It is characterized as a research of qualitative content, using field research along with semi-structured interviews with transgendered people who have completed basic education. Data were analyzed through content analysis. The results showed that basic education and physical education, in your most, still are characterized as discrimination environments and of great impact for these people, having as a conclusion of the interviewer and the interlocutors that the best way to develop the contents would be through mixed classes, with more open about gender and sexuality.

KEYWORDS: Genus. Transsexual. School. Physical Education.

\section{EDUCACIÓN FÍSICA ESCOLAR: LOS IMPACTOS SOCIALES EN LA VIDA DE PERSONAS TRANSEXUALES EN BELÉM DO PARÁ}

RESUMEN: Este artículo investiga la influencia de la educación, específicamente la educación física con las personas transgénero de Belém do Pará. Pretende describir las contribuciones positivas, negativas o indiferentes de la educación y educación física, antes de la vida social de las personas 
transgénero. Se caracteriza por ser una investigación de contenido cualitativo, utilizando la investigación de campo y entrevistas semiestructuradas con las personas transexuales que han completado la educación básica. Los datos fueron analizados a través de análisis de contenido. Los resultados mostraron que la educación básica y la educación física, en su mayoría, son todavía caracteriza los ambientes de segregadores y de gran impacto para estas personas, teniendo como una conclusión del entrevistador y los interlocutores que la mejor manera de desarrollar los contenidos a través de clases mixtas, con más abierta sobre género y sexualidad.

PALABRAS CLAVES: De género. Transexual. Escuela. Educación física.

\section{REFERÊNCIAS}

BARRETO, Andreia; ARAÚJO, Leila; PEREIRA, Maria Elisabete. Gênero e diversidade na escola: formação de professoras/ES em gênero, orientação sexual e relações étnico-raciais. Rio de Janeiro: CEPESC; Brasília: SPM, 2009.

BUTLER, Judith. Problemas de gênero- Feminismo e subversão da identidade. Rio de Janeiro: Ed. Civilização Brasileira, 1ª Edição, 2003.

CARTILHA PARA A DIVERSIDADE. População LGBT: Um guia da cidadania no Pará - Conceitos, Direitos Humanos, Políticas Públicas, Espaços, Conquistas e Participação Social. Secretaria de Estado de Justiça e Direitos Humanos - SEJUDH; Gerência de Proteção à Livre Orientação Sexual GLOS/SEJUDH, Belém - Pará, 2017.

DAOLIO, Jocimar. Da cultura do corpo. Campinas: Papirus, 1995.

DORNELLES, Priscila Gomes. 'Distintos destinos': problematizando as relações de gênero nas aulas separadas entre meninos e meninas na Educação Física escolar. PPGEdu/UFRGS, Anais do VII Seminário Fazendo Gênero, 2006.

DORNELLES, Priscila Gomes; FRAGA, Alex Branco. Aula Mista Versus Aula Separada? Uma Questão De Gênero Recorrente Na Educação Física Escolar. Revista Brasileira de Docência, Ensino e Pesquisa em Educação Física - ISSN 2175-8093 - Vol. 1, n. 1, p.141-156, Agosto/2009.

FRANZINI, Fábio; Futebol é "Coisa pra macho"? Pequeno esboço para uma história das mulheres no país do futebol. Revista Brasileira de História. São Paulo, v. 25, n 50, 2005.

FRANCO, Neil. A Educação Física Como Território De Demarcação Dos Gêneros Possíveis: vivências escolares de pessoas travestis, transexuais e transgêneros. Motrivivência v. 28, n. 47, p. 47-66, maio/2016.

FREITAS; Ana Paula Araújo de. SILVEIRA, Nicia Luíza Duarte da. Ética Na Pesquisa Com Sujeitos Humanos: Aspectos a destacar para investigadores iniciantes. Psicol. Argum. 26(52), 35-46, jan./mar, 2008. 
GERHARDT, Tatiana Engel; SILVEIRA, Denise Tolfo. Métodos de pesquisa. Universidade Aberta do Brasil - UAB/UFRGS e pelo Curso de Graduação Tecnológica - Planejamento e Gestão para o Desenvolvimento Rural da SEAD/UFRGS. - Porto Alegre: Editora da UFRGS, 2009.

GOELLNER, Silvana Vilodre. A produção cultura do corpo. In: LOURO, Guacira Lopes; FELIPE, Jane; GOELLNER, Silvana V. (Org). Corpo, gênero e sexualidade: Um debate contemporâneo na educação. 2. Ed. Petrópolis, RJ: Vozes, 2003, p. 28-40.

JAYME, Juliana Gonzaga; Travestis, Transformistas, Drag-Queen, Transexuais: identidade, corpo e gênero. Comunicação a Ser Apresentada Ao VIII Congresso Luso-Afro-Brasileiro de Ciências Sociais, no Painel Sexualidades Minoritárias? Identidades, Associações e Movimentos LGBT. 2004.

JESUS, Jaqueline Gomes de; Orientações sobre identidade de gênero: Conceitos e termos - Guia técnico sobre pessoas transexuais, travestis e demais transgêneros, para formadores de opinião. $2^{a}$ edição - revista e ampliada. Brasilia, dez - 2012.

JUNQUEIRA, Rogério Diniz. Pedagogia do armário e currículo em ação: heteronormatividade, heterossexismo e homofobia no cotidiano escolar. Discursos fora da Ordem: deslocamentos, reinvenções e direitos. São Paulo: Annablume, 2012. (Série Sexualidades e Direitos Humanos).

LOURO, Guacira Lopes; Gênero, Sexualidade e Educação - Uma perspectiva pós-estruturalista:; Editora Vozes - 6a edição, 2003.

LOURO, Guacira Lopes; O Corpo Educado - Pedagogias da Sexualidade. Belo Horizonte: Autêntica, 1999.

OLIVEIRA, Valéria Rodrigues de. Desmistificando a pesquisa científica. Belém, Editora Universitária UFPA, 2008.

PIRES, Pierre André Garcia. A Escola E Sua Contribuição Na Formação De Sujeitos: Um Olhar A Partir Da Nova Concepção De Currículo. In - Linguagem e Cultura: Múltiplos Olhares, 2013.

PRINCÍPIOS DE YOGYAKARTA - Princípios sobre a aplicação da legislação internacional de direitos humanos em relação à orientação sexual e identidade de gênero. Indonésia, 2007.

SOUZA, Heloisa Aparecida de; BERNARDO, Marcia Hespanhol; Transexualidade: as consequências do preconceito escolar para a vida profissional. Bagoas. N. 11, 2014.

WILM, Lucas; Compreendendo o que é orientação sexual, identidade, expressão e papel de gênero. In Corpo Transitivo - transgeneridade, orientação sexual, teoria queer, transfeminismo, recorte de raça, lesbianidade, \&+. 1a Edição, Belém - Pará. 2016. 
BARROSO, L.B.; CARDOSO, W.R.S.; MESQUITA, M.R.

Lucas Bernardo Barroso: Graduado em Educação Física pela Universidade do Estado do Pará (UEPA). Primeira trans a ter nome social reconhecido pela Universidade do Estado do Pará

E-mail: lucasbe.barroso@smail.com

Wladirson Ronny Da Silva Cardoso: Bacharel/Licenciado em Filosofia, Mestre em Direitos Humanos e Inclusão Social e Doutor em Antropologia. Líder do "COGITANS' Grupo de Estudos e Pesquisa em Filosofia Moderna e Contemporânea" e Professor da UEPA e do Curso de Mestrado do Programa de Pós-Graduação em Currículo e Gestão da Escola Básica da Universidade Federal do Pará (PPEB/UFPA).

E-mail: wladirson.cardoso@gmail.com

Marcelo Ribeiro De Mesquita: Professor da Rede Municipal de Belém e Mestrando Programa de Pós Graduação em Currículo e Gestão da Escola Básica da Universidade Federal do Pará (PPEB/UFPA).

E-mail: tchelorm81@gmail.com 